\title{
Curbs on B6 highlight dietary dilemmas
}

[LONDON] Protests from the health-food industry and from some scientists have persuaded almost 100 members of the British parliament to resist proposals to limit over-the-counter sales of vitamin B6. The MPs have signed a motion opposing legislation, now being prepared by the government, that would restrict sales of the vitamin on safety grounds.

The row about the proposed regulation highlights the problems that many governments face in controlling the use of vitamins and other dietary supplements, which are increasingly used medicinally but rarely regulated in the same way as medicines.

The Ministry of Agriculture, Fisheries and Food (MAFF) wrote to MPs last week with information about the vitamin in an attempt to influence their opinion before the vote on the proposed legislation comes up perhaps next month. The legislation would limit the amount of vitamin B6 on open sale to $10 \mathrm{mg}$ per day. Doses of between 10 and 50 mg per day would be available for sale only under the supervision of a pharmacist, while doses between 50 and $200 \mathrm{mg}$ would be prescription-only.

Vitamin B6 is registered as a drug in the British National Formulary, the official drug register, but because of controversy about toxicity the Medicines Control Agency, which is part of the Department of Health $(\mathrm{DoH})$, is reviewing the conditions of the licence it issued for B6.

The daily recommended intake for $\mathrm{B} 6$ as a vitamin is less than $1.5 \mathrm{mg}$ per day, but higher doses - typically between 50 and $200 \mathrm{mg}$ per day - are widely used to control symptoms of pre-menstrual tension and the side-effects of the contraceptive pill.

No-one disputes that very high doses of vitamin B6 taken over long periods can cause symptoms of peripheral neurotoxicity (nerve damage). But controversy exists about the exact dose that can be deemed safe.

Opponents of the proposed legislation dispute its scientific basis and argue that the public should be free to buy B6 in doses up to $200 \mathrm{mg}$ unless a health risk can be proved.

But the Consumers' Association argues that the scientific basis for concern about the safety of even a 50-mg dose is strong. The association claims the government has mishandled the affair and that this has fed the power of the opposition lobby. Last year, the association asked MAFF to consider the evidence for vitamin-B6 toxicity as part of its general concern that regulation of dietary supplements languishes in a 'no-man's land', falling between the two sets of rules controlling food and medicine.

MAFF referred the matter to the $\mathrm{DoH}$, whose independent Committee on Toxicity in Food, Consumer Products and the

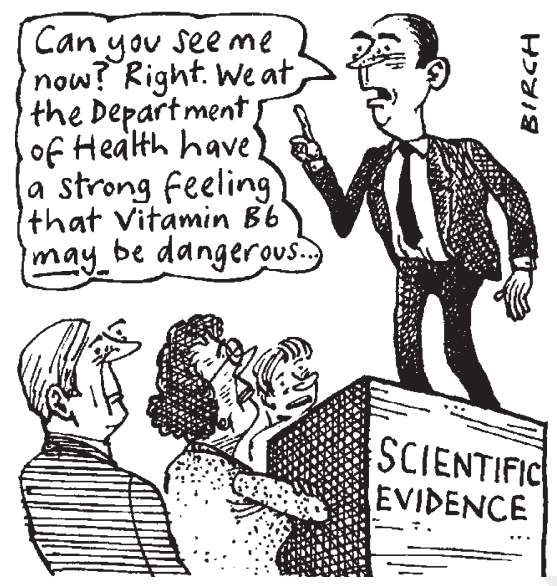

Environment (COT) in July recommended restricting sales. The Royal Pharmaceutical Society of Great Britain endorsed the decision and major supermarkets cleared their shelves of all dietary supplements that included high-dose B6. Meanwhile, the government prepared to draft legislation.

The DoH has not published the full details of COT's scientific deliberations, but a short statement from COT indicates that the committee focused on a 10-year-old study which relies on subjective measures of symptoms. COT acknowledges what it calls the study's "methodological difficulties", but considers it particularly relevant because it concerns patients taking 50-mg doses. COT's statement also refers to its consideration of other studies involving patients taking very high doses of up to $500 \mathrm{mg}$.

Liz Sheppard, public affairs officer of the Consumers' Association, believes the statement gives a wrong impression of the committee's deliberations. It does not mention, for example, that the committee also referred to well over 600 adverse drug reactions that have been reported by doctors prescribing B6 in the 20 years since it was licensed as a medicine. "This evidence has obviously been critical in the government's decision," Sheppard says.

The health-food manufacturers' lobby has found it easy to pick holes in the scientific arguments in COT's statement. As well as criticizing the quality of studies quoted by COT, the lobby argues that the safety factor applied by COT, to arrive at its maximum safe dose of $10 \mathrm{mg}$, is arbitrary. According to COT's rules, safe doses are calculated by determining usually in animal studies - at what level no adverse symptoms are observed; applying a factor of 10 to compensate for differences between animals and humans; and applying an additional factor of 10 to compensate for variability among individuals.

The manufacturers argue, with the support of some scientists, that applying these factors to essential vitamins is not appropriate. Arnold Beckett, a professor of pharmaceutics at the University of London and a former president of the Pharmaceutical Society, points out that if the same safety factors were applied to caffeine, supermarkets would have to clear their shelves of coffee.

But Sheppard argues that the whole debate could have been avoided if the $\mathrm{DoH}$ had properly explained the scientific basis of its recommendation.

The United Kingdom is not alone in worrying about the possible dangers of B6. The European Union is considering a move to harmonize member countries' systems of dietary supplement control, which vary considerably. In a report on vitamin B6, the union's Scientific Committee for Food has said that "intakes of more than $50 \mathrm{mg}$ per day must... be regarded as potentially harmful".

In the United States, vitamin B6 is freely available for sale, but manufacturers have set a voluntary limit on doses of $200 \mathrm{mg}$. This may change when a Food and Drug Administration report on dietary supplements is completed in two years' time. Alison Abbott

\section{Flood control strategy agreed for Oder}

[MUNICH] Germany, Poland and the Czech Republic have agreed on closer

collaboration in flood management

following the recent catastrophic flooding of the River Oder, which runs through all three countries. Lack of coordination in managing the river has been widely criticized as contributing to the severity of flood damage.

The environment ministers of the three countries and the German state of Brandenburg met last month to determine how best to work together to reduce the consequences of any future floods.

A joint flood management strategy will now be established between the three countries. It will include ecological measures, such as the protection and creation of flood plains to buffer peak flows, and the development of simulation models for forecasting floods.

Some German university institutes have offered research proposals for the development of flood models to the Brandenburg environment ministry.

The environment ministers called on the help of the International Commission Against Oder Pollution (IKSO), representing Germany, Poland, the Czech Republic and the European Union, which was set up in 1996 with the aim of developing a collaborative strategy for water protection in the region. Matthias Strobl 